\title{
CONF-9706176-
}

\author{
Presented at: High Aspects Ration Micro Systems Technology (HARMST) ‘97 \\ Madison, WI \\ June 20-21, 1997
}

BNL- 64630

\section{High Speed Hydraulic Scanner for Deep X-ray Lithography}

J. C. Milne and E. D. Johnson

Brookhaven National Laboratory

Upton, NY 11973-5000

July 1997

\section{DISCLAIMER}

This report was prepared as an account of work sponsored by an agency of the United States Government. Neither the United States Government nor any agency thereof, nor any of their employees, makes any warranty, express or implied, or assumes any legal liability or responsibility for the accuracy, completeness, or usefulness of any information, apparatus, product, or process disclosed, or represents that its use would not infringe privately owned rights. Reference herein to any specific commercial product, process, or service by trade name, trademark, manufacturer, or otherwise does not necessarily constitute or imply its endorsement, recommendation, or favoring by the United States Government or any agency thereof. The views and opinions of authors expressed herein do not necessarily state or reflect those of the United States Government or any agency thereof.

National Synchrotron Light Source

Brookhaven National Laboratory

Upton, NY 11973

Work performed under the auspices of the U.S. Department of Energy, under contract DE-AC02-76CH00016. 


\section{DISCLAMMER}

Portions of this document may be illegible in electronic image products. Images are produced from the best available original document. 


\section{High Speed Hydraulic Scanner for Deep X-ray Lithography \\ J. Christopher Milne and Erik D. Johnson \\ Brookhaven National Laboratory, Upton, New York, 11973}

From our research and development in hard x-ray lithography, we have found that our conventional leadscrew driven scanner stages do not provide adequate scan speed or travel. These considerations have led us to develop a scanning system based on a long stroke hydraulic drive with $635 \mathrm{~mm}$ of travel and closed loop feedback to position the stage to better than 100 micrometers. The control of the device is through a PC with a custom LabView interface coupled to simple x-ray beam diagnostics. This configuration allows us to set a variety of scan parameters, including target dose, scan range, scan rates, and dose rate. Results from our prototype system at beamline X-27B are described as well as progress on a production version for the $\mathrm{X}-14 \mathrm{~B}$ beamline.

\subsection{Introduction}

The National Synchrotron Light Source has initiated a deep $\mathrm{x}$-ray lithography (DXRL) program utilizing the unique properties of its X-ray storage ring. Our R\&D beamline X-27B has been used for this purpose for several years. The program has demonstrated the compelling advantages derived from the relatively high photon energy and high flux density available at the NSLS $x$-ray ring for exposing resist (polymethylmethacrylate (PMMA)) in thickness' of $10 \mathrm{~mm}$ or more (Siddons et al (1994) and Johnson et al (1996)). The success of X-27B program motivated us to initiate construction of a production exposure station at beamline $\mathrm{X}-14 \mathrm{~B}$, which we hope to make available in early 1998.

In our development of the $\mathrm{X}-27 \mathrm{~B}$ exposure station, we utilized a variety of existing mechanical scanning devices. They were all gear reduction leadscrew drives, powered by stepper motors. These stages were actually designed to serve other functions (positioning optics for example), and were less than satisfactory for lithography exposures due to limitations such as small scan range, low scan speed, and low mechanical durability. 
Our 'best' previous scan stage possessed a limited $(-140 \mathrm{~mm})$ scan distanceand a low scan speed $(\sim 5 \mathrm{~mm} / \mathrm{s})$. It also suffered from motor acceleration resonances which would cause the scanner to lose its position or to stop moving altogether. Although this system served us well and yielded useful results, it was clear we needed to replace it with one which would provide us with a larger operating window for our research. After considering several alternative approaches, we decided to develop a non-leadscrew based device, and ultimately settled on the hydraulic system described in this work.

\subsection{Design Considerations}

As the process of designing the new scan stage progressed, it became apparent that a hydraulic system would allow us to incorporate several desirable features that would prove difficult to obtain with a leadscrew-based system. While performing DXRL exposures with our old leadscrew-based system, we determined that a significant amount of time was spent decelerating and then accelerating the scan stage after each pass through the x-ray beam. One approach to reduce the impact of this "dead time" is to expose several substrates during the same scan. To do so the scan stage must be able to provide a long stroke. This turns out to be readily achieved with a hydraulic cylinder. For our prototype scanner we selected a cylinder with a $635 \mathrm{~mm}$ stroke.

It also became clear from our previous experiments that significant improvements in resist processing are realized by exposing with relatively low dose rates while maintaining a relatively high integrated dose, which can be achieved by increasing the scanning rate. For our hydraulic system scan rates as high as $250 \mathrm{~mm} / \mathrm{s}$ are possible. To maintain a constant integrated dose, the number of scan cycles will increase with the scan speed. In practice this implies that the scanner must run with essentially $100 \%$ duty factor and cycle up to $\sim 25,000$ strokes per day.

In our new system, we retained some of the attractive characteristics of our original scanner system. The scanner operates under computer control for positioning and scan velocity. Spatial resolution is better than 100 microns, while the scan velocity is accurate to better than one $\mathrm{mm} / \mathrm{s}$. This is important, as an errant scan velocity would skew any integrated dose calculations. The motion of this stage is smooth and repeatable which is 
an important feature since a uniform dose (and dose rate) is required to provide good resist processing characteristics. Finally, we designed the stage with the minimum requirement of being able to move fixtures and instruments weighing up to 75 pounds.

\subsection{Reduction to Practice}

The prototype scanner is shown in figure 1. The scan stage working platform rides on a group of three vertical rods guided by circulating ball bushings. The hydraulic cylinder is used to raise and lower the platform, on which the mask holder and resist fixturing are mounted. A linear voltage differential transducer (LVDT) coupled to the stage provides closed loop position feedback. The cylinder is driven by a commercially available hydraulic power unit and actuated by a computer-controlled servo-valve.

The hydraulic power unit in this system has a 5-gpm pump backed with a 20 gallon reservoir. It is equipped with the usual provisions for such systems; air bleed, supply and return line filters, and a pressure gauge with an isolator. The system typically operates at 400 psi with very low noise. The hydraulic cylinder is also commercially available, having a $38 \mathrm{~mm}$ bore and $635 \mathrm{~mm}$ stroke.

\section{FIGURE 1 (PROTOTYPE SCANNER) SHOULD BE PLACED} APPROXIMATELY HERE

An LVDT was chosen for position feedback because it has no rubbing parts subject to fatigue failure, which is an important consideration for a device that must run for millions of cycles between failures. The signal from the LVDT is processed and used as feedback for the cylinder servo-valve. The servo amplifier requires two analog inputs of zero to 10 volts for operation; one input determines the scan velocity (valve opening), and the other the position (LVDT offset). When a new position signal is received, the actuator will proceed toward that point at the set speed. The maximum speed of 250 $\mathrm{mm} / \mathrm{s}$ corresponds to $10 \mathrm{~V}$ while the minimum speed at zero volts is $\sim 0.25 \mathrm{~mm} / \mathrm{s}$. The maximum stroke of $635 \mathrm{~mm}$ corresponds to a voltage input of $10 \mathrm{~V}$. A 16-bit digital-toanalog $(\mathrm{D} / \mathrm{A})$ card for use in a personal computer provides these signals. The LabView 
programming language was used to program and access the D/A card. Several additional features have been incorporated into the scan stage control software, which include acceleration/deceleration routines, and real-time velocity adjustments in response to external control signals. This last feature is what allows the system to maintain constant dose rate in response to changes in $\mathrm{x}$-ray flux.

\subsection{Status and Summary}

Commissioning of the assembled prototype system began in September of 1996. Since that time, the scan stage system has seen over 400 hours of scanning operation and performed over $3.1 \times 10^{5}$ cycles (including an 8-hour period where over $1.6 \times 10^{4}$ cycles were executed), with zero hours of downtime due to component failure. The system has met all of our design criteria, and the overall performance of the hydraulic based scan stage has exceeded our expectations. The system has also demonstrated its versatility, allowing us to control many aspects of its operation in real-time. The success of this prototype system has led us to select it as the technical basis for the scanner in our new DXRL station X-14B (Milne and Johnson (1997)).

Many of the features of the prototype are retained in our production station scanner. As designed, the X-14B scanner will have a maximum scan distance of $525 \mathrm{~mm}$, which will allow up to 4 five-inch substrates to be exposed simultaneously. The scanner will also be capable of scan speeds up to $250 \mathrm{~mm} / \mathrm{s}$. Based on feedback from outside groups who have used the X-27B scan system, the graphical user interface used to integrate the scanner controls system on X-27B will be ported directly to X-14B. The X-14B scanner will also incorporate computer controlled chilled water and helium for temperature and humidity control. 


\subsection{References}

Siddons, D.P; Johnson E.D.; Gückel H. (1994) Precision Machining with Hard X-rays. Synchrotron Radiation News; Vol. 7, No. 2:16-18

Johnson E.D.; Milne J.C.; Siddons, D.P; Gückel H.; Klein J.L.; (1996) Precision Machining with Hard X-rays: Experiments at the NSLS. Synchrotron Radiation News; Vol. 9, No. 4:10-13

Johnson E.D.; Milne J.C. (1997) A Hard X-ray Prototype Production Exposure Station at NSLS These proceedings.

The NSLS is supported by the United States Department of Energy under contract DEAC02-76CH00016. 
Figure 1: The prototype hydraulic scanner used at beamline X-27B. The lift table is kinematically located inside the $\mathrm{x}$-ray hutch, and the scanner raised to approximate beam height. Not shown is the hydraulic power unit (pump and fluid reservoir) which is located outside the $x$-ray hutch.

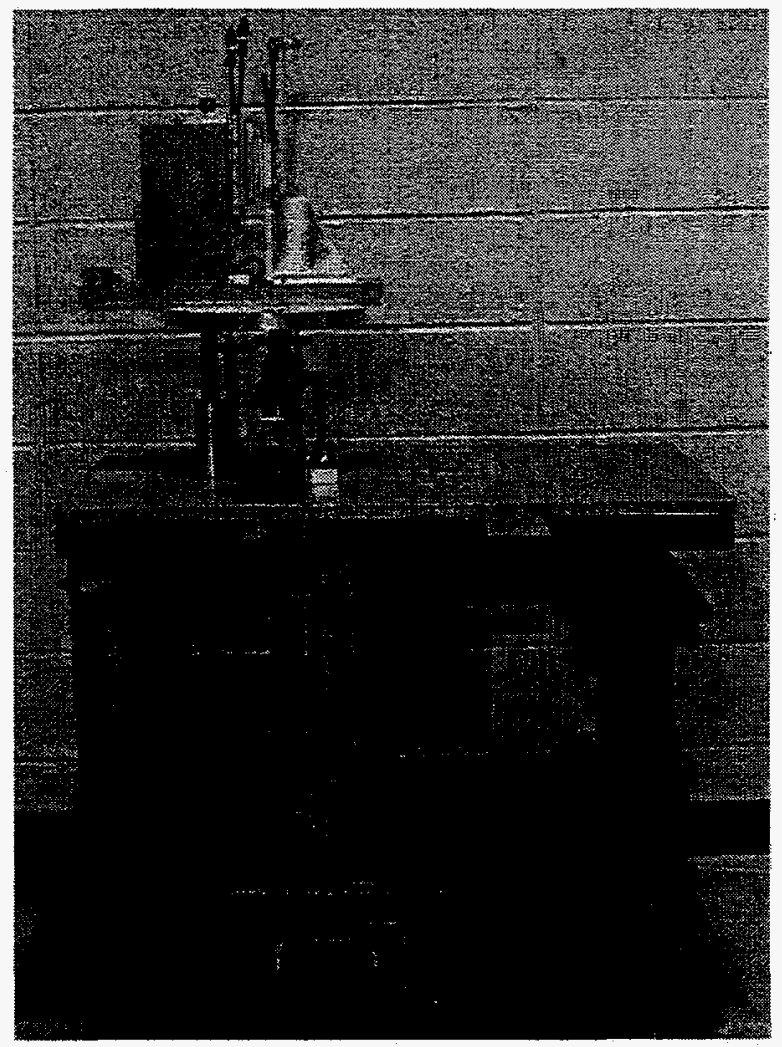

